\title{
Risk of prostate, ovarian, and endometrial cancer among relatives of women with breast cancer
}

\author{
Hrafn Tulinius, Valgarđur Egilsson, Guđríđur H Ólafsdóttir, Helgi Sigvaldason
}

\begin{abstract}
Objective-To investigate the risk of prostate, ovarian, and endometrial cancer among relatives of patients with breast cancer.

Design-Cohort study of 947 pedigrees in which the proband had breast cancer, linked with the Icelandic cancer registry.

Setting-Iceland.

Subjects-The 947 pedigrees included 29725 people, of whom 1539 had breast cancer, 467 had prostate cancer, 135 ovarian cancer, and 105 endometrial cancer.

Main outcome measures-Risk of prostate, ovarian, and endometrial cancer among blood relatives of women with breast cancer compared with risk in spouses.

Results-The risk of prostate cancer was significantly raised for all relatives $(1 \cdot 5)$, first degree relatives $(1 \cdot 4)$, and second degree relatives $(1 \cdot 3)$ of women with breast cancer. Risk of ovarian cancer was raised for all relatives (1.9) and first degree relatives (1.9) and risk of endometrial cancer was raised for all relatives only (1.9). The risk of prostate cancer was raised if the proband with breast cancer had a first degree relative with prostate cancer.

Conclusions-Coaggregation exists between breast cancer and cancers of the prostate, ovaries, and endometrium. This risk relation is probably based on genes which act by increasing the risk for cancer at these sites. Environmental factors that are common among relatives may also play a part. Continued research is required into pathophysiological mechanisms that could explain these observations.
\end{abstract}

\section{Introduction}

A cohort study using an Icelandic breast cancer family resource has shown that, in conformity with most published studies, female relatives of women with breast cancer have an increased risk of developing breast cancer.' The increased risk was found in all relatives measured together, and in first, second, and third degree relatives measured separately. We investigated the cohort further to determine the risk of prostate, ovarian, and endometrial cancer among relatives of the women with breast cancer. We also show a method for indicating the overall risk for all relatives using values representing degree of relatedness.

\section{Subjects and methods}

The Icelandic breast cancer family resource contains 947 pedigrees in which the proband is a woman with breast cancer. ' We determined cases of cancer occurring during 1955-88 in family members born during 1870 to 1939 who were aged 45 or older. Table I shows that there were 9299 female relatives and 9278 male relatives born during 1870-1939 in addition to 10201 people married into the families.

We avoided recall bias by obtaining the information on which family members had cancer from a register of all Icelandic people with cancer. A list of all family of members was crosslinked with the register by using a unique personal identification number. Classification 0 bias was avoided by selecting the probands on the basis of year of birth or year of diagnosis only, and by 0 defining in advance how far each pedigree should go. 0 The information for constructing the family tree was obtained from existing records of the genetics committee of the University of Iceland or from published genealogies. The family members were thus not asked about the structure of their family or about $\mathbb{\Phi}$ cancer in the family.

\section{STATISTICAL METHODS}

The risk period for cancer was taken as 1955-88. Each individual was assumed to be at risk from the beginning of the period or from the age of 45 , whichever came later, until the end of 1988 , death, or diagnosis of cancer, whichever came first.

Observed cases of cancer and years of risk in family $\overrightarrow{\vec{O}}$ members were classified according to sex, calendar decades of birth (1870-1939), five year age intervals, and degree of relatedness to the breast cancer proband (first degree, second degree, third degree, and fourth degree relatives, and spouse of a proband or a relative). Classification was also done according to whether the proband had a first degree relative with breast cancer or 3 prostate cancer, whether the proband had bilateral or unilateral cancer, and whether her cancer was diagnosed before or after the age of 45 .

Data were analysed by Poisson regression with the package EGRET, ${ }^{2}$ and rate ratios and their $95 \% \stackrel{N}{\sigma}$ confidence intervals were calculated. As the results $\frac{D}{2}$ seemed to justify collapsing the degrees of relatedness into one variable this was performed by using the $N$ values shown in table III.

The expected number of cases of prostate cancer in 0 each type of relative was also calculated as a sum of products of incidence figures for Iceland and number of risk years. Both were classified according to five year $\stackrel{\mathcal{P}}{+}$ age groups and five year calendar periods.

\section{Results}

Risk ratios for breast, ovarian, endometrial, and prostate cancer were first determined for five year age groups with the age group 45-49 taken as the reference range (table II). Risk ratios for decades of birth relative to 1870-79 were then determined. These are also $\frac{0}{7}$ shown in table II. The risk ratio was significantly? dependent on age group for all four types of cancer but was dependent on decade of birth for only breast and prostate cancer. 
Table III shows the risk ratios for first, second, third, and fourth degree relatives compared with spouses. The risk ratios were significantly raised for ovarian cancer in first degree relatives; for prostate cancer in first and second degree relatives; and breast cancer in first, second, and third degree relatives. Risk ratios for endometrial cancer were not raised for separate degree relatives. Table III also shows overall risk ratios for relatedness; the risk of all four types of cancer was significantly raised.

Relatives of probands who had cancer diagnosed when younger than 45 or probands with bilateral breast cancer did not have a significantly increased risk of prostate cancer.

Table IV shows the results of simultaneous testing for increased risk of prostate cancer in second degree and more distant relatives of women with breast cancer when the proband had first degree relatives with prostate cancer or breast cancer. In both cases the risk was significantly raised. The increase in risk of breast cancer associated with the proband having a relative with breast cancer was significant only after correction for relatives with prostate cancer. The relative risk of prostate cancer in husbands of probands compared with husbands of relatives of probands was $0 \cdot 8(95 \%$ confidence interval 0.4 to $1 \cdot 5$ ).

In addition to the Poisson regression we calculated the expected number of cases of prostate cancer (Table

TABLE I-Total number of people studied and number of cases of breast, ovarian, endometrial, and prostate cancer

\begin{tabular}{|c|c|c|c|c|c|}
\hline & \multirow{2}{*}{$\begin{array}{l}\text { No of } \\
\text { people }\end{array}$} & \multicolumn{4}{|c|}{ No of cancer cases } \\
\hline & & Breast & Ovary & Endometrium & Prostate \\
\hline Probands & 947 & 947 & & & \\
\hline Male blood relatives & 9299 & & & & 321 \\
\hline Female blood relatives & 9278 & 545 & 96 & 76 & \\
\hline Husbands of probands & 656 & & & & 11 \\
\hline Husbands of relatives & 4762 & & & & 135 \\
\hline Wives of relatives & 4783 & 165 & 39 & 29 & \\
\hline Total & 29725 & 1657 & 135 & 105 & 467 \\
\hline
\end{tabular}

TABLE II-Risk ratios for cancer (95\% confidence intervals) according to age and year of birth in relatives of breast cancer probands and spouses of relatives and probands

\begin{tabular}{|c|c|c|c|c|}
\hline & \multicolumn{4}{|c|}{ Site of cancer } \\
\hline & Breast & Ovary & Endometrium & Prostate \\
\hline \multicolumn{5}{|l|}{ Age: } \\
\hline 45-49 (reference) & 1 & 1 & 1 & 1 \\
\hline $50-54$ & $1.8(1.3$ to 2.5$)$ & $2 \cdot 7(1 \cdot 4$ to $5 \cdot 1)$ & $4.3(2.0$ to 8.9$)$ & $6 \cdot 3(1.4$ to 28.7$)$ \\
\hline $55-59$ & $2.5(1.9$ to 3.4$)$ & $2.5(1.3$ to 5.0$)$ & $2.5(1.0$ to 6.0$)$ & $49.2(13.8$ to 176 \\
\hline $60-64$ & $2.9(2.1$ to 3.9$)$ & $2.8(1.4$ to 5.7$)$ & $2.9(1.2$ to 7.3$)$ & $123(34$ to 449$)$ \\
\hline $65-69$ & $4 \cdot 0(2 \cdot 8$ to $5 \cdot 6)$ & $3.7(1.8$ to 7.6$)$ & $6.5(2 \cdot 7$ to $15 \cdot 6)$ & $288(79$ to 1047$)$ \\
\hline $70-74$ & $4 \cdot 8(3 \cdot 3$ to $7 \cdot 1)$ & $3.7(1.7$ to 8.3$)$ & $10 \cdot 3(4 \cdot 1$ to $25 \cdot 7)$ & 666 (182 to 2434$)$ \\
\hline $75-79$ & $6.6(4.3$ to 10.0$)$ & $3.9(1.6$ to 9.5$)$ & $13.6(5.3$ to 35.0$)$ & 734 (199 to 2714 ) \\
\hline $80-84$ & $7 \cdot 1(4 \cdot 3$ to $11 \cdot 6)$ & $6.8(2 \cdot 8$ to $16 \cdot 7)$ & $11.1(3.7$ to 33.1$)$ & $1699(459$ to 6288$)$ \\
\hline$\geqslant 85$ & $16 \cdot 1(10.0$ to $25 \cdot 8)$ & $1.8(0.4$ to 8.9$)$ & $2.4(0.3$ to $20 \cdot 8)$ & 1921 (509 to 7246 ) \\
\hline \multicolumn{5}{|l|}{ Year of birth: } \\
\hline $1870-9$ (reference) & 1 & 1 & 1 & 1 \\
\hline $1880-9$ & $1.8(0.8$ to 4.1$)$ & $0.1(0.0$ to 1.5$)$ & $0.6(0.1$ to 6.0$)$ & $1.7(0.8$ to 3.3$)$ \\
\hline $1890-9$ & $1.9(0.9$ to 4.2$)$ & $1.3(0.3$ to 5.8$)$ & $1.8(0.2$ to $13 \cdot 6)$ & $1.9(1.0$ to 3.7$)$ \\
\hline $1900-9$ & $2.0(0.9$ to 4.4$)$ & $1.2(0.3$ to 5.5$)$ & $2 \cdot 1(0.3$ to $16 \cdot 4)$ & $2.8(1.4$ to 5.4$)$ \\
\hline $1910-9$ & $4.0(1.8$ to 9.1$)$ & $1.4(0.3$ to 6.5$)$ & $1.9(0.2$ to $15 \cdot 6)$ & $4.3(2 \cdot 2$ to 8.7$)$ \\
\hline $1920-9$ & $6 \cdot 1(2 \cdot 6$ to $14 \cdot 2)$ & $1.3(0.3$ to 6.4$)$ & $3.7(0.4$ to 31.3$)$ & $6 \cdot 6(3 \cdot 1$ to $14 \cdot 2)$ \\
\hline $1930-9$ & $3.8(1.6$ to 9.2$)$ & $0.8(0.1$ to 4.2$)$ & $1.9(0.2$ to 17.8$)$ & $8.4(2.6$ to 27.4$)$ \\
\hline
\end{tabular}

TABLE III-Risk ratios for cancer (95\% confidence intervals) in blood relatives of breast cancer probands compared with risk in spouses of relatives

\begin{tabular}{|c|c|c|c|c|}
\hline & \multicolumn{4}{|c|}{ Site of cancer } \\
\hline & Breast & Ovary & Endometrium & Prostate \\
\hline Spouses & 1.0 & 1.0 & $1 \cdot 0$ & 1.0 \\
\hline 1st Degree & $2.3(1.8$ to 3.0$)$ & $1.9(1.2$ to 3.0$)$ & $1.7(0.97$ to 3.0$)$ & $1.4(1.1$ to 1.9$)$ \\
\hline 2nd Degree & $1.7(1.3$ to 2.1$)$ & $1.2(0.7$ to 1.9$)$ & $1.6(0.97$ to 2.7$)$ & $1.3(1.0$ to 1.6$)$ \\
\hline 3rd Degree & $1.6(1.3$ to 2.1$)$ & $0.8(0.5$ to 1.4$)$ & $0.9(0.5$ to 1.6$)$ & $1.0(0.8$ to 1.3$)$ \\
\hline 4th Degree & $1.5(0.9$ to 2.4$)$ & $2.1(0.9$ to 4.9$)$ & $0.9(0.2$ to 3.9$)$ & $1 \cdot 1(0.5$ to $2 \cdot 6)$ \\
\hline Relatedness* & $2 \cdot 1(1.7$ to 2.7$)$ & $1.9(1.2$ to 3.1$)$ & $1.9(1.1$ to 3.2$)$ & $1.5(1.1$ to 1.9$)$ \\
\hline
\end{tabular}

* Relatedness (kinship coefficient $\times 4$ ) takes the following values: first degree relatives $=1$, second degree relatives $=$ $1 / 2$, third degree relatives $=1 / 4$, fourth degree relatives $=1 / 8$, spouses of relatives and probands $=0$.
TABLE IV-Risk ratios for prostate cancer in second, third, and fourth degree relatives of breast cancer probands according to whether the proband had a first degree relative with cancer

\begin{tabular}{lcc}
\hline Type of cancer in relative & Risk ratio & $95 \%$ Confidence interval \\
\hline None (reference) & 1.0 & \\
Prostate cancer & 1.8 & 1.4 to 2.4 \\
Breast cancer & 1.3 & 1.0 to 1.7 \\
\hline
\end{tabular}

TABLE V-Observed and expected numbers of cases of prostate cancer in relatives of breast cancer probands

\begin{tabular}{|c|c|c|c|}
\hline & Observed & Expected & $\begin{array}{c}\text { Risk ratio } \\
(95 \% \text { confidence interva }\end{array}$ \\
\hline First degree relatives: & 78 & $56 \cdot 9$ & $1.37(1.09$ to 1.71$)$ \\
\hline Father & 37 & $25 \cdot 5$ & $1.45(1.02$ to 2.00$)$ \\
\hline Brother & 35 & $27 \cdot 1$ & $1.29(0.90$ to 1.79$)$ \\
\hline Son & 6 & $4 \cdot 3$ & $1.40(0.51$ to 3.05$)$ \\
\hline Second degree relatives & 156 & $131 \cdot 8$ & $1.18(1.01$ to 1.38$)$ \\
\hline Third degree relatives & 81 & $86 \cdot 0$ & $0.94(0.75$ to 1.18$)$ \\
\hline Spouses of probands & 11 & $13 \cdot 3$ & $0.83(0.41$ to 1.49$)$ \\
\hline Spouses of relatives & 135 & $141 \cdot 6$ & $0.95(0.80$ to 1.12$)$ \\
\hline
\end{tabular}

V). The risk of prostate cancer in spouses of the proband's relatives was similar to that in the whole population and the risk ratios for the various types op relatives were comparable with those obtained byo Poisson regression. Spouses of probands have nog increased risk of prostate cancer.

\section{Discussion}

Our most important finding is that male relatives of women with breast cancer are at excess risk of prostate्ष cancer, both when all relatives are taken together and when first and second degree relatives are consideredo separately. A case-control study based on data from ar $\mathrm{N}$ American hospital found the same-that is, eight cases of prostate cancer were found among relatives of women with breast cancer (six fathers, one uncle, anc one brother) compared with one case among relative of control women (one father).

Cannon et al studied 2824 men with prostate cance and age matched controls from the Utah Mormon genealogy. ${ }^{4}$ They showed a significant clustering of prostate cancer within families as well as significan clustering of prostate cancer with breast cancer. Both of these conclusions have been confirmed in this study A high incidence of prostatic cancer has been recorded in Icelandic families with a history of breast cance (A Arason et al, personal communication). In twö families certain haplotypes on the chromosome 17 h seem to be linked to both prostate and breast cancer. In families without linkage to that region, men with prostatic cancer seem to pass on the risk of early onsef of breast cancer to their daughters.

Syndromes of familial aggregation of breast and ovarian cancer, and of breast cancer and cancer at otherv sites, have been described. ${ }^{5-9}$ A population based case-control study (the cancer and steroid hormonestudy) reported that the risk of ovarian cancer was increased by $1.7(95 \%$ confidence interval 1.0 to 2.9$)$ in first degree relatives of women with breast cancer. The risk was subsequently shown to be confined to firsto degree relatives and to be stronger in mothers than in sisters. " We found a weighted relative risk of 1.9 fo ovarian cancer, which was also confined to first degreep relatives.

Linkage studies of families in which members had breast cancer diagnosed at a young age, and cancer of the ovaries, suggested a linkage between a locus or the long arm of chromosome 17 and risk of breas cancer. ${ }^{1213}$ The results were interpreted as indicating monogenetic, dominant inheritance.

As can be seen in table III the Poisson regression loses power when the data are divided into more and 
more classes. A significant increase in risk of endometrial cancer is found for relatedness when all the relatives are taken together but not for each type of relative. The same applies to risk of prostate cancer according to cancer in first degree relatives of the probands. When second degree and more distant relatives are divided into five classes according to whether the proband had first degree relatives with prostate, breast, ovarian, or endometrial cancer or none, the only significant increase in risk was for prostate cancer. When the categories considered were restricted to prostate cancer, breast cancer, and neither, a significantly increased risk of breast cancer was also found.

Body mass has been suggested as a confounding factor. Body mass index has been reported to be a risk factor for breast cancer ${ }^{14}$ or prostate cancer. ${ }^{15}$ But in Icelandic cohort studies it was not found a significant risk factor for any of the cancer sites considered in this study. ${ }^{1617}$ For breast cancer, however, both height and weight independently were positive risk factors, as were body surface and lean body mass. General lifestyle factors may affect husband and wife in a similar way. We therefore tested whether the husbands of the probands had an increased risk of prostate cancer when compared with husbands of female relatives. No indication of increased risk. in husbands of probands was found.

The results suggest that the familiality of breast cancer is heterogeneous in that the increase in risk of breast and prostate cancer in relatives of probands is not confined to first degree relatives, as it is among endometrial and ovarian cancer. The power of this study to show an increased risk among second degree relatives is considerably stronger for prostate cancer than for ovarian cancer.

We thank the genetics committee of the University of Iceland, which developed the system allowing construction of pedigrees of Icelanders. This has provided most of the information necessary for the family trees reported on in this publication. This study was supported by the research fund of the Icelandic Cancer Society.

1 Tulinius H, Sigvaldason H, Olafsdóttir G, Tryggvadóttir L. Epidemiology of breast cancer in families in Iceland. $\mathcal{F}$ Med Genet 1992;29:158-64.

2 Statistics and Epidemiology Research Corporation. EGRET reference manual. Seattle: SERC, 1990

3 Thiessen EU. Concerning a familial association between breast cancer and both prostatic and uterine malignancies. Cancer 1974;34:1102-7.

4 Cannon L, Bishop D, Skolnick M, Hunt S, Lyon JL, Smart CR. Genetic epidemiology of prostate cancer in the Utah Mormon genealogy. Cancer Surveys 1982:1:47-69.

5 Lynch HT, Harris RE, Guirgis HA, Maloney K, Carmody LL, Lynch JF. Familial association of breast/ovarian carcinoma. Cancer 1978;41:1543-9.

6 Lynch HT, Albano WA, Lynch JE, Lynch PM, Campbell A. Surveillance and management of patients of high genetic risk for ovarian carcinoma. Obstet Gynecol 1982;59:589-96.

7 King MC, Go RCP, Elston RC, Lynch HT, Petrakis NL. Allele increasing susceptibility to human breast cancer may be linked to the glutamatepyruvate transaminase locus. Science 1980;208:406-8.

8 Williams WR, Anderson DE. Genetic epidemiology of breast cancer: $\vec{O}$ segregation analysis of 200 Danish pedigrees. Genet Epidemiol 1984;1:7-20.

9 Ferrell RE, Anderson DE, Chidambaram A, Marino TR, Badzioch M. A genetic linkage study of familial breast-ovarian cancer. Cancer Genet $\omega$ Cytogenet 1989;38:241-8.

10 Schildkraut JM, Risch N, Thompson WD. Evaluating genetic association among ovarian, breast and endometrial cancer: evidence for a breast/ovarian cancer relationship. Am 7 Hum Genet 1989;45:521-9.

11 Thompson WD, Schildkraut JM. Family history of gynecological cancers: relationships to the incidence of breast cancer prior to age 55. Int $\gamma$ Epidens: 1991,20:595-602.

12 Hall JM, Lee MK, Newman B, Morrow JE, Anderson LA, Huey B, et al. Linkage of early-onset familial breast cancer to chromosome 17q21. Science 1985;250:1684-9.

13 Narod SA, Feunteun J, Lynch HT, Watson P, Conway T, Lynch J, et al. G Familial breast-ovarian cancer locus on chromosome 17q12-q23. Lancet 1991;338:82-3

14 Vatten LJ, Kvinnsland S. Body mass index and risk of breast cancer. A prospective study of 23,826 Norwegian women. Int $\mathcal{C}$ Cancer 1990;45:440-4.

15 Nomura AMY, Kolonel LN. Prostate cancer: a current perspective. Epidemiologic Reviews 1991;13:200-27.

16 Tulinius H, Sigfússon N, Sigvaldason H, Day NE. Can anthropometric and biochemical measurements illustrate the diet-cancer connection? Näringsforskning 1985;29:17-22.

17 Tulinius H, Sigfússon N, Sigvaldason H, Day NE. Relative weight and human cancer risk. In: Joosens JV, Hill MJ, Gebors J, eds. Diet and human 21st Gum 1985, Ams Congress Series No 685 .)

(Accepted 20 August 1992)

\title{
Epilepsy in the first 10 years of life: findings of the child health and education study
}

\author{
C M Verity, E M Ross, Jean Golding
}

\section{Abstract}

Objectives-To identify children with afebrile seizures in a national cohort, classify the seizures, and document progress in the first 10 years of life.

Design-Population based birth cohort study.

Setting-The child health and education study, which includes 16004 neonatal survivors $(98 \cdot 5 \%$ of infants born in the United Kingdom during one week of April 1970).

Subjects-14676 children for whom relevant information was available.

Main outcome measures-Responses to parental and general practitioner questionnaires and hospital records at 5 and 10 years after birth.

Results -84 children ( 42 boys, 42 girls) had had one or more afebrile seizure (incidence 5·7/1000). 63 children ( 31 boys, 32 girls) had epilepsy (incidence 4.3/1000). 49 of 55 children had a second seizure within a year of the first. The commonest seizure types were tonic-clonic (42) and complex partial (25). A greater proportion of children with complex partial seizures had recurrences. Children who had infantile spasms or a mixed seizure disorder had a poor outcome. All six children who died had symptomatic seizures in the first year, but seizures were not the direct cause of death.
Conclusions-The results of this study are probably representative of seizure patterns in the general population. Outcome after seizures is determined more by the underlying disease than by the seizures themselves.

\section{Introduction}

The child health and education study has prospectively followed a cohort of 16004 neonatal survivors born in one week in April 1970. Detailed clinical information was obtained about children suspected of having seizures. Only a few studies have been large $\stackrel{\oplus}{\oplus}$ enough to obtain similar data about seizure disorders in childhood. ${ }^{1-4}$ This paper reports on the study children who had had one or more afebrile seizures by 10 years of age.

\section{Subjects and methods}

The child health and education study started as the 1970 British births survey. ${ }^{5}$ This survey enrolled $98.5 \%$ of the infants born in the United Kingdom in one week in April 1970; 13135 (82\%) of the survivors were assessed at 5 years of age and $14902(93 \%)$ at 10 years. As part of both assessments the parents were 